\title{
Molecular Imaging of Hypoxia
}

\author{
Satish K. Chitneni ${ }^{1}$, Gregory M. Palmer ${ }^{2}$, Michael R. Zalutsky ${ }^{1,2}$, and Mark W. Dewhirst ${ }^{2}$ \\ ${ }^{1}$ Department of Radiology, Duke University Medical Center, Durham, North Carolina; and ${ }^{2}$ Department of Radiation Oncology, \\ Duke University Medical Center, Durham, North Carolina
}

\begin{abstract}
A wide variety of imaging approaches have been developed in the past few decades for monitoring tumor oxygenation and hypoxia in vivo. In particular, nuclear medicine has seen the development of several radiolabeled hypoxia markers and is the preferred method for imaging of tumor hypoxia. Hypoxia imaging is increasingly being used in the clinical setting and is progressing from a mere detection method to application in individualization of chemoradiotherapy.
\end{abstract}

Key Words: hypoxia; PET; optical imaging; nitroimidazole

J Nucl Med 2011; 52:165-168

DOI: 10.2967/jnumed.110.075663

Since its first observation by Tomlinson and Gray in $\mathbf{1 9 5 5}$, tumor hypoxia has become a central issue in cancer treatment. Hypoxia can occur when the oxygen requirements of a tumor exceed those that can be delivered by its vasculature. Structural abnormalities of microvessels and the limited diffusion distance $(<70 \mu \mathrm{m})$ of $\mathrm{O}_{2}$ within the tumor create hypoxic regions with partial pressure of $\mathrm{O}_{2}\left(\mathrm{pO}_{2}\right)$ typically less than $10 \mathrm{~mm} \mathrm{Hg}$. A recent review (1) described the following characteristics, which are often present in tumors, as contributing to impaired oxygen transport and hypoxia: a relatively sparse arteriolar supply; a high $\mathrm{O}_{2}$ consumption rate; low vascular density; inefficient orientation of blood vessels; intense variations in red blood cell flux, resulting in regions of cycling hypoxia; a limited arteriolar supply, which can lead to pathologically low vascular $\mathrm{pO}_{2}$ in regions distant from the arteriolar source (longitudinal $\mathrm{O}_{2}$ gradient); sluggish blood flow due to stiffening of hypoxic red blood cells and increased blood viscosity; and large-diameter shunts that can divert blood away from the tumor bed, resulting in regions of low $\mathrm{pO}_{2}$.

Tumors often adapt to hypoxic environments by upregulation of the transcription factor hypoxia-inducible factor 1 (HIF-1). HIF-1 is a heterodimer protein composed of $\mathrm{O}_{2}$-sensitive HIF- $1 \alpha$ and constitutively expressed HIF-1 $\beta$ subunits. When stabilized by hypoxic conditions, HIF-1 binds and transactivates several of the genes associated with enhanced glycolysis, angiogenesis, and promotion of cell survival under oxidative stress. These characteristics eventually confer tumors with higher degrees of invasiveness and resistance to chemoradiation therapy. Consequently,

Received Jul. 27, 2010; revision accepted Sep. 23, 2010.

For correspondence or reprints contact: Mark W. Dewhirst, Department of Radiation Oncology, Box 3455 DUMC, Room 201 MSRB, Research Dr., Duke University Medical Center, Durham, NC 27710.

E-mail: dewhi001@mc.duke.edu.

COPYRIGHT @ 2011 by the Society of Nuclear Medicine, Inc. patients with hypoxic tumors often have a poor prognosis and decreased overall survival rate. Therefore, the ability to detect hypoxia within tumors has significant implications for cancer management and therapy. The current gold standard for in vivo measurement of tumor oxygenation is the Eppendorf needle electrode system, which allows for direct measurement of $\mathrm{pO}_{2}$ in tumors. However, it is an invasive procedure that often requires ultrasound-guided placement of the electrode, and its use is limited to easily accessible tumors.

Immunohistochemical methods are extensively used to detect and quantify hypoxia in patient biopsies. They are typically based on antibody binding to bioreductive nitroimidazole compounds that are systemically administered before the biopsy is performed (e.g., pimonidazole, 2-(2-nitro- ${ }^{1} \mathrm{H}$-imidazol-1-yl)- $N$-(2,2,3,3,3pentafluoropropyl)-acetamide [EF5]) or to endogenous proteins that are overexpressed under hypoxic conditions (e.g., HIF- $1 \alpha$, carbonic anhydrase IX). The main limitations of these techniques are their invasiveness, limited sampling size, and the inability to perform repetitive measurements in a patient to monitor changes in oxygenation after therapies. Because of the heterogeneous and dynamic nature of hypoxia in tumors, noninvasive techniques that permit serial imaging of hypoxia could provide valuable information on disease status and for treatment planning. Although hypoxia also occurs in other pathologic conditions including myocardial ischemia and stroke, hypoxia imaging is much more advanced in oncology applications such as prediction of response to therapy and overall prognosis. Therefore, this review focuses on the potential and current status of monitoring oxygenation and hypoxia in tumors. Both optical and PET methods will be discussed.

\section{OPTICAL METHODS OF MEASURING TUMOR OXYGENATION AND HYPOXIA}

Optical spectroscopy enables quantification of intrinsic sources of optical absorption, scattering, and fluorescence in tissue. There are 2 major sources of contrast relevant to hypoxia: hemoglobin oxygen saturation $\left(\mathrm{StO}_{2}\right)$ and fluorescence redox ratio. Hemoglobin is the dominant tissue absorber throughout the visible spectrum. The heme groups of hemoglobin bind oxygen, which changes their absorption spectrum. Quantification of absorption at several wavelengths enables determination of the fraction of heme that is bound to oxygen $\left(\% \mathrm{StO}_{2}\right)$. The fluorescence redox ratio quantifies the autofluorescence associated with the electron carriers reduced nicotinamide adenine dinucleotide and flavin adenine dinucleotide (and related derivatives such as reduced nicotinamide adenine dinucleotide phosphate). The former is fluorescent only in its reduced form, whereas the latter is fluorescent only when oxidized (2). The ratio of the autofluorescence contributed by these compounds has thus been used as a ratiometric indicator of tissue metabolic activity. 
Diffuse reflectance spectroscopy, also known as light-scattering spectroscopy, enables quantification of bulk tissue absorption and scattering. Measuring diffuse reflectance as a function of wavelength enables quantification of tissue absorption and scattering using quantitative models of light-tissue interaction (3). These measurements are commonly made using a fiber-optic probe placed in contact with the tissue surface, providing a spot-based modality for quantification of $\mathrm{StO}_{2}$ and fluorescence redox ratio. This has potential application for quantifying tissue hypoxia both as a prognostic or diagnostic tool and as a way to monitor the response to therapy. For example, Vishwanath et al. recently demonstrated that early changes in oxygenation in response to radiation treatment are predictive of control in a xenograft model (Fig. 1) (4). Scanning or wide-field approaches using noncontact methods or placement of an array of sensors enables extension of this approach to imaging and the potential for some limited depthsensing capabilities (3). Related imaging modalities include hyperspectral imaging, diffuse optical tomography, and photoacoustic imaging, all of which are capable of characterizing $\mathrm{StO}_{2}$. Hyperspectral imaging quantifies transmitted or reflected light as a function of wavelength, commonly using multiple emission filters or a tunable filter. This has been applied to window chamber tumor models and endoscopic applications and is capable of high-resolution imaging of hemoglobin saturation $(5,6)$. This technique has also recently been applied to imaging the fluorescence redox ratio, providing dual-modality characterization of oxygen supply and metabolism (7). Diffuse optical tomography involves placement of an array of sources and detectors to enable 3-dimensional reconstruction of tissue optical properties (8). Because of the need for deep-penetrating photons, near-infrared light is used. Tissue absorption is exceptionally low in this spectral range; thus, it is commonly referred to as the near-infrared window. This technique has been used to explore oxygenation in the cortex (commonly applied in a 2-dimensional mapping approach known as diffuse optical topography) (9), as well as in diagnosis and therapeutic monitoring of breast cancer. This method enables deep-tissue imaging $(\sim 10-\mathrm{cm}$ depth); however, resolution is limited by tissue scattering, typically being on the order of $1 \mathrm{~cm}$ at a depth of about $10 \mathrm{~cm}$. Finally, optoacoustic imaging exploits ultrasonic perturbations induced by absorption of light by hemoglobin. This enables deep-tissue functional imaging with optical contrast specificity, combined with the submillimeter resolution of ultrasound (10). Disadvantages include the complexity of the instrumentation and modeling algorithms, need for a high-power source for sample illumination, and long imaging times, although improvements in hardware continue to be made and clinical instruments are now being developed.

\section{PET OF TUMOR HYPOXIA}

Detection of tumor hypoxia with radionuclides was first demonstrated in 1981 by autoradiography with ${ }^{14} \mathrm{C}$-misonidazole, which selectively bound to metabolizing hypoxic cells within the tumor (11). Subsequently, ${ }^{18} \mathrm{~F}$-misonidazole was proposed as a PET tracer for noninvasive imaging of tumor hypoxia. Since then, several other tracers also have been evaluated for this purpose, including ${ }^{18} \mathrm{~F}$-fluoroazomycin arabinoside ( $\left.{ }^{18} \mathrm{~F}-\mathrm{FAZA}\right), \mathrm{Cu}(\mathrm{II})$ diacetyl-bis $\left(N^{4}\right.$-methylthiosemicarbazone) (Cu-ATSM) labeled with ${ }^{60 / 64} \mathrm{Cu}$, and ${ }^{18} \mathrm{~F}-\mathrm{EF} 5$ (Table 1 ). Readers are referred to recent reviews by Mees et al. (12) and Krohn et al. (13) for detailed discussion of these tracers. With the exception of $\mathrm{Cu}$-ATSM, these

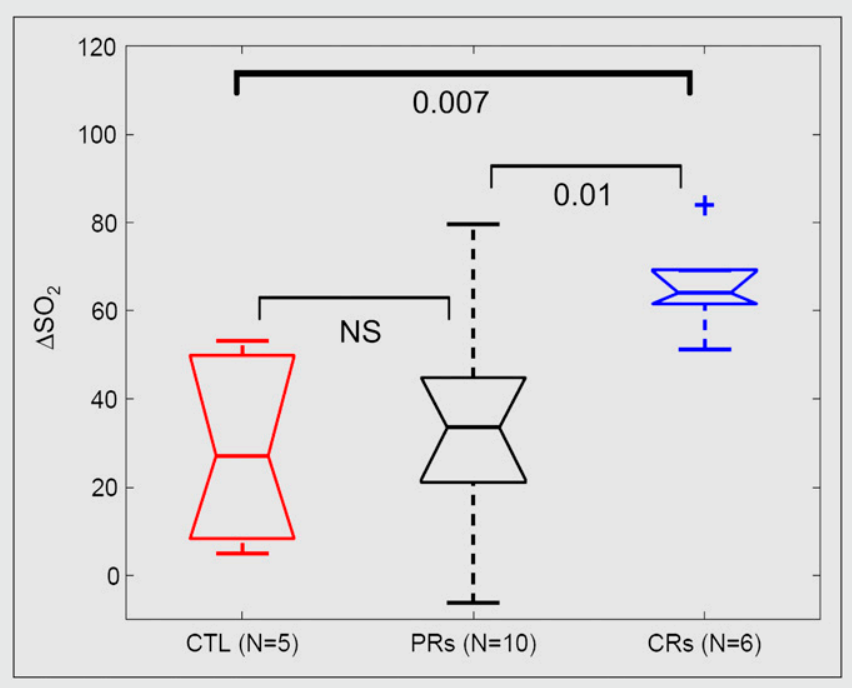

FIGURE 1. Change in hemoglobin oxygen saturation $\left(\mathrm{StO}_{2}\right)$ $14 \mathrm{~d}$ after 1-time dose of 39 Gy (median tumor control dose). Tumors that were controlled locally by radiation showed larger increase in oxygenation than those that failed to be controlled or control animals that were not irradiated. This difference was significant as early as $7 \mathrm{~d}$ after treatment. $P$ values are shown for pairwise Wilcoxon signed rank test. CTL = control; $\mathrm{CR}=$ complete response; NS = not statistically significant; PR = partial response. (Reprinted with permission of (4).)

compounds are 2-nitroimidazoles, and their retention in hypoxic cells is based on their ability to undergo sequential reduction reactions yielding products that bind to macromolecules within the cell. An ideal tracer for tumor hypoxia imaging should be specific for hypoxia, and its uptake should reflect clinically relevant cellular $\mathrm{pO}_{2}$ values $(0-10 \mathrm{~mm} \mathrm{Hg})$ irrespective of the tumor type and grade. An ideal tracer should also allow for radiolabeling without significant loss of biologic properties, be lipophilic enough to have uniform tissue distribution but hydrophilic enough to have faster clearance from systemic circulation and nonhypoxic tissue, and rapidly accumulate in tumor to give high tumor-tobackground ratios at early times after injection. Absolute uptake in the tumor should be high to minimize patient radiation dose, and the tracer should have high stability against non-hypoxiadependent metabolism in vivo.

Although none of the currently available tracers have all the properties of an ideal hypoxia imaging agent, ${ }^{18} \mathrm{~F}$-misonidazole remains the most extensively studied agent. The selection of which imaging agent to use depends largely on, for example, tumor type, ease of synthesis, and availability of radioisotope. Several studies have validated the use of ${ }^{18} \mathrm{~F}$-misonidazole PET for quantification of hypoxia in a variety of tumors, including head and neck cancer, nonsmall cell lung cancer, soft-tissue sarcoma, renal cell carcinoma, breast cancer, and brain tumors (14). These studies have used an ${ }^{18} \mathrm{~F}$-misonidazole tumor-to-blood activity ratio of at least $1.2-1.4$ at $2-2.5 \mathrm{~h}$ as the cutoff for defining hypoxia. The ability of ${ }^{18} \mathrm{~F}$-misonidazole PET to provide prognosis and predict response to treatment has also been validated. In some studies, repeated PET of patients receiving chemotherapy or radiation therapy showed a reduction in tumor hypoxic fraction after treatment. The Trans-Tasmanian Radiation Oncology Group Study reported that hypoxia PET can identify cancer patients who may benefit from hypoxia-specific cytotoxins such as tirapazamine (15). Head and neck cancer patients with 


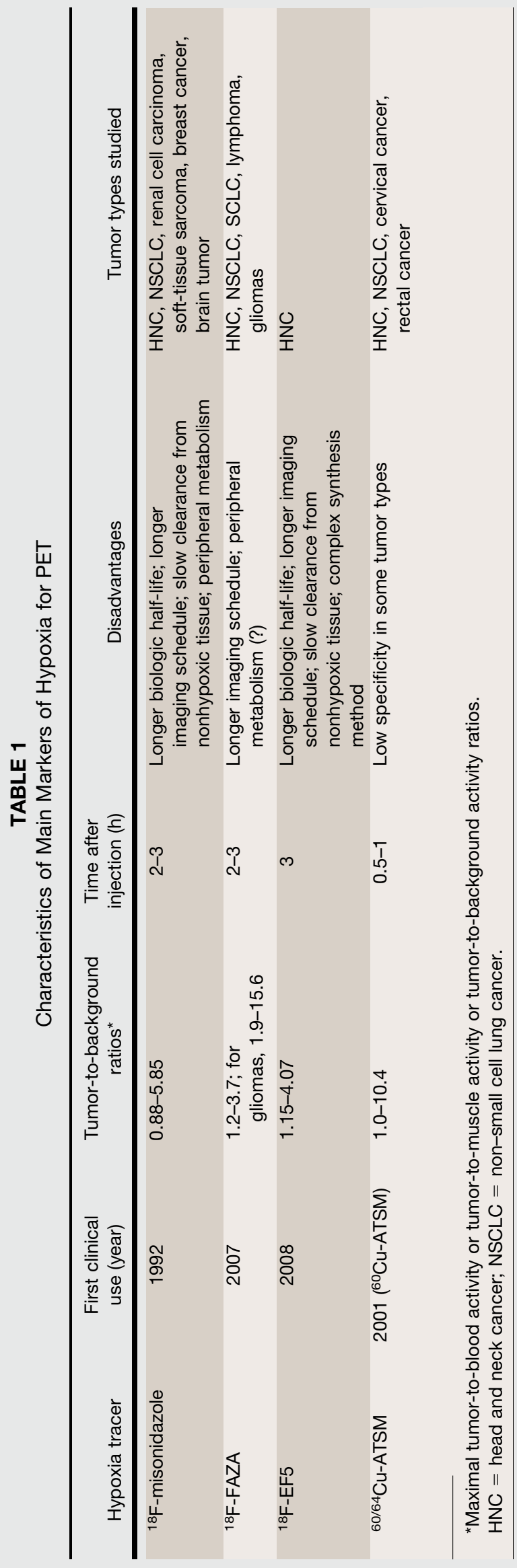

hypoxic tumors treated with a non-tirapazamine-containing regimen showed a higher risk for locoregional failure than did patients receiving tirapazamine. Nehmeh at al. evaluated the reproducibility of ${ }^{18}$ F-misonidazole PET scans in head and neck cancer patients and showed that tracer intratumoral distribution may vary between 2 scans (16). This variation can primarily be attributed to the cycling of acute tumor hypoxia, which has important implications for the use of ${ }^{18} \mathrm{~F}$-misonidazole PET as a basis for dose painting in intensitymodulated radiotherapy (Fig. 2).

${ }^{18} \mathrm{~F}$-fluoroazomycin arabinoside (FAZA) is a 2-nitroimidazole hypoxia imaging agent with the alkyl side chain in ${ }^{18} \mathrm{~F}$-misonidazole replaced by a polar arabinose sugar in an attempt to increase the overall hydrophilicity of the compound. Accordingly, ${ }^{18} \mathrm{~F}-\mathrm{FAZA}$ was cleared more quickly from blood and normal tissues in animal studies and provided higher tumor-to-muscle ratios than did ${ }^{18} \mathrm{~F}$ misonidazole. Similar to ${ }^{18} \mathrm{~F}$-misonidazole, ${ }^{18} \mathrm{~F}$-FAZA was found to be useful for imaging hypoxia in various tumors (18). In patients with glioblastoma multiforme, ${ }^{18} \mathrm{~F}$-FAZA yielded remarkably high tumor-to-background ratios due to selective and presumably hypoxia-specific uptake in tumor reflecting blood-brain barrier disruption. ${ }^{18} \mathrm{~F}-\mathrm{FAZA}$ does not cross the intact blood-brain barrier because of its hydrophilic nature, resulting in minimal uptake in normal brain. Grosu et al. have shown that ${ }^{18} \mathrm{~F}$-FAZA PET can be used to define the target volume for dose escalation in radiation treatment planning (19). On the basis of current clinical experience, ${ }^{18} \mathrm{~F}-\mathrm{FAZA}$ shows considerable promise for imaging hypoxia; how-
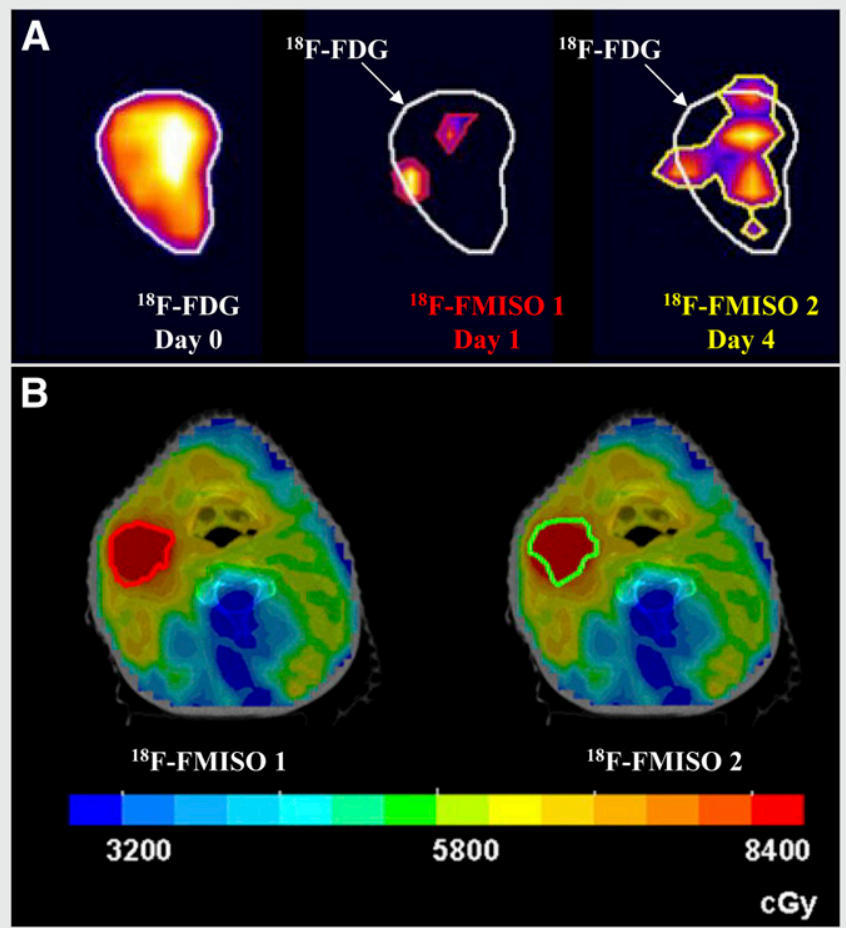

FIGURE 2. (A) ${ }^{18} \mathrm{~F}$-misonidazole (FMISO) PET scans obtained $3 \mathrm{~d}$ apart in patient with head and neck cancer show large variations in size and distribution of hypoxic regions between scans. Tumor volume was defined by viable tumor tissue that showed ${ }^{18} \mathrm{~F}$-FDG uptake. (B) Intensity-modulated radiotherapy dose distributions in color-wash display of patient whose sequential ${ }^{18} \mathrm{~F}$-misonidazole PET scans were similar. Hypoxic target volume was defined from first scan (outlined in red), and boost dose of $14 \mathrm{~Gy}$ was delivered to this zone in addition to 70-Gy prescription dose. (Reprinted with permission of $(18,19)$.) 
ever, a direct comparison between ${ }^{18} \mathrm{~F}-\mathrm{FAZA}$ and ${ }^{18} \mathrm{~F}$-misonidazole in patients has yet to be performed.

${ }^{18} \mathrm{~F}-\mathrm{EF} 5$, another 2-nitroimidazole being developed for hypoxia imaging, is a pentafluoro derivative of the hypoxic cell sensitizer etanidazole and is prepared by electrophilic addition of ${ }^{18} \mathrm{~F}-\mathrm{F}_{2}$ to the terminal double bond of the precursor. In designing EF5, Koch et al. used an opposing strategy to that of ${ }^{18} \mathrm{~F}$-FAZA. They chose to enhance the lipophilicity of the compound by introducing 5 fluorine atoms to the nitroimidazole side chain to increase its biologic half-life and stability in vivo. ${ }^{18} \mathrm{~F}$-EF5 is the most lipophilic 2-nitroimidazole hypoxia imaging agent with the longest biologic half-life. It has a unique advantage: EF5 in nonradioactive form has been extensively studied as a marker for hypoxia using fluorescence immunohistochemistry, and high EF5 binding was found to predict patient outcome. Other advantages of ${ }^{18} \mathrm{~F}-\mathrm{EF} 5$ are its uniform access to all tissues, including the brain, and its high in vivo stability. The first human study of ${ }^{18}$ F-EF5 demonstrated hypoxia-specific binding in head and neck cancer. Similar to ${ }^{18} \mathrm{~F}$-misonidazole, a tumor-to-muscle threshold of 1.5 has been suggested to define clinically significant hypoxia with ${ }^{18} \mathrm{~F}-\mathrm{EF} 5$ (20).

$\mathrm{Cu}$-ATSM is a nonnitroimidazole compound that is most commonly labeled with ${ }^{60} \mathrm{Cu}$ (half-life, $24.5 \mathrm{~min}$ ) or ${ }^{64} \mathrm{Cu}$ (halflife, $12.7 \mathrm{~h}$ ) for PET of tumor hypoxia (21). In the presence of hypoxia, Cu-ATSM is trapped intracellularly in the $1 \mathrm{e}^{-}$reduced form, $\mathrm{Cu}(\mathrm{I})$-ATSM. It provides high tumor-to-background ratios $(\leq 10.4)$ in less than $1 \mathrm{~h}$ after injection. Clinical studies have shown that $\mathrm{Cu}$-ATSM can predict tumor response to therapy in cervical cancer, non-small cell lung cancer, and, to a lesser extent, rectal cancer. Its uptake in tumors is inversely correlated with progression-free and overall survival in cervical and rectal cancers (22). A direct comparison of ${ }^{60} \mathrm{Cu}-\mathrm{ATSM}$ and ${ }^{64} \mathrm{Cu}-\mathrm{ATSM}$ scans separated by $1-9$ d in cervical cancer patients showed similar patterns and magnitudes of uptake, indicating the reproducibility and, most likely, the chronic hypoxia-dependent uptake of $\mathrm{Cu}-$ ATSM. However, ${ }^{64} \mathrm{Cu}$-ATSM yielded better-quality images with slightly higher tumor-to-background ratios than did ${ }^{60} \mathrm{Cu}$-ATSM (23). All clinical studies conducted with Cu-ATSM so far have used images acquired at less than $1 \mathrm{~h}$ after injection for evaluation of tumor hypoxia. Evidence from experimental studies suggests that the hypoxia selectivity of Cu-ATSM varies among different tumor types and that its uptake in some tumor types at 1-2 $\mathrm{h}$ after administration may not truly reflect hypoxia (24).

\section{CONCLUSION}

At present, there is no consensus on the best radiotracer for imaging hypoxia with PET. ${ }^{18} \mathrm{~F}$-misonidazole, ${ }^{18} \mathrm{~F}-\mathrm{FAZA}$, and $\mathrm{Cu}$-ATSM have demonstrated potential value in clinical studies; however, head-to-head comparison of these agents is necessary to reveal the optimal agent for a given tumor type. Although the search for an "ideal" hypoxia imaging agent is likely to continue, current PET hypoxia imaging methods already show promise for selection of patients who are likely to benefit from hypoxia-directed treatment regimens such as intensity-modulated radiotherapy, hypoxic cytotoxins, or HIF-1 inhibitors.

\section{ACKNOWLEDGMENTS}

This work was supported by grants from Varian Medical Systems, the DOD (W81XWH-07-1-0355), and the NIH (CA42324 and CA40355).

\section{REFERENCES}

1. Dewhirst MW, Cao Y, Moeller B. Cycling hypoxia and free radicals regulate angiogenesis and radiotherapy response. Nat Rev Cancer. 2008;8: 425-437.

2. Chance B, Schoener B, Oshino R, Itshak F, Nakase Y. Oxidation-reduction ratio studies of mitochondria in freeze-trapped samples: NADH and flavoprotein fluorescence signals. J Biol Chem. 1979;254:4764-4771.

3. Brown JQ, Vishwanath K, Palmer GM, Ramanujam N. Advances in quantitative UV-visible spectroscopy for clinical and pre-clinical application in cancer. Curr Opin Biotechnol. 2009;20:119-131.

4. Vishwanath K, Klein D, Chang K, Schroeder T, Dewhirst MW, Ramanujam N. Quantitative optical spectroscopy can identify long-term local tumor control in irradiated murine head and neck xenografts. J Biomed Opt. 2009;14: 054051 .

5. Shonat RD, Wachman ES, Niu W, Koretsky AP, Farkas DL. Near-simultaneous hemoglobin saturation and oxygen tension maps in mouse brain using an AOTF microscope. Biophys J. 1997;73:1223-1231.

6. Sorg BS, Moeller BJ, Donovan O, Cao Y, Dewhirst MW. Hyperspectral imaging of hemoglobin saturation in tumor microvasculature and tumor hypoxia development. J Biomed Opt. 2005;10:44004.

7. Skala MC, Fontanella A, Lan L, Izatt J, Dewhirst M. Longitudinal optical imaging of tumor metabolism and hemodynamics. J Biomed Opt. 2010;15: 011112 .

8. Gibson AP, Hebden JC, Arridge SR. Recent advances in diffuse optical imaging. Phys Med Biol. 2005;50:R1-43.

9. Koizumi H, Yamamoto T, Maki A, et al. Optical topography: practical problems and new applications. Appl Opt. 2003;42:3054-3062.

10. Wang LV. Multiscale photoacoustic microscopy and computed tomography. Nat Photonics. 2009;3:503-509.

11. Chapman JD, Franko AJ, Sharplin J. A marker for hypoxic cells in tumours with potential clinical applicability. Br J Cancer. 1981;43:546-550.

12. Mees G, Dierckx R, Vangestel C, Van de Wiele C. Molecular imaging of hypoxia with radiolabelled agents. Eur J Nucl Med Mol Imaging. 2009;36: 1674-1686.

13. Krohn KA, Link JM, Mason RP. Molecular imaging of hypoxia. J Nucl Med. 2008;49(suppl): 129S-148S.

14. Lee ST, Scott AM. Hypoxia positron emission tomography imaging with ${ }^{18} \mathrm{~F}$ fluoromisonidazole. Semin Nucl Med. 2007;37:451-461.

15. Rischin D, Hicks RJ, Fisher R, et al. Prognostic significance of ${ }^{18} \mathrm{~F}$-misonidazole PET-detected tumor hypoxia in patients with advanced head and neck cancer randomly assigned to chemoradiation with or without tirapazamine: a substudy of Trans-Tasman Radiation Oncology Group Study 98.02. J Clin Oncol. 2006; 24:2098-2104.

16. Nehmeh SA, Lee NY, Schroder H, et al. Reproducibility of intratumor distribution of ${ }^{18} \mathrm{~F}$-fluoromisonidazole in head and neck cancer. Int $J$ Radiat Oncol Biol Phys. 2008;70:235-242.

17. Lin Z, Mechalakos J, Nehmeh S, et al. The influence of changes in tumor hypoxia on dose-painting treatment plans based on ${ }^{18} \mathrm{~F}-\mathrm{FMISO}$ PET. Int $J$ Radiat Oncol Biol Phys. 2008;70:1219-1228.

18. Postema EJ, McEwan AJB, Riauka TA, et al. Initial results of hypoxia imaging using 1- $\alpha$-D-(5-deoxy-5- ${ }^{18}$ F-fluoroarabinofuranosyl)-2-nitroimidazole $\left({ }^{18} \mathrm{~F}-\mathrm{FAZA}\right)$. Eur J Nucl Med Mol Imaging. 2009;36:1565-1573.

19. Grosu AL, Souvatzoglou M, Roper B, et al. Hypoxia imaging with FAZA-PET and theoretical considerations with regard to dose painting for individualization of radiotherapy in patients with head and neck cancer. Int J Radiat Oncol Biol Phys. 2007;69:541-551.

20. Komar G, Seppanen M, Eskola O, et al. ${ }^{18}$ F-EF5: a new PET tracer for imaging hypoxia in head and neck cancer. J Nucl Med. 2008;49:1944-1951.

21. Vavere AL, Lewis JS. Cu-ATSM: a radiopharmaceutical for the PET imaging of hypoxia. Dalton Trans. 2007;4893-4902.

22. Dehdashti F, Grigsby PW, Lewis JS, Laforest R, Siegel BA, Welch MJ. Assessing tumor hypoxia in cervical cancer by PET with ${ }^{60} \mathrm{Cu}$-labeled diacetyl-bis $\left(N^{4}\right.$ methylthiosemicarbazone). J Nucl Med. 2008;49:201-205.

23. Lewis JS, Laforest R, Dehdashti F, Grigsby PW, Welch MJ, Siegel BA. An imaging comparison of ${ }^{64} \mathrm{Cu}$-ATSM and ${ }^{60} \mathrm{Cu}$-ATSM in cancer of the uterine cervix. J Nucl Med. 2008;49:1177-1182.

24. O'Donoghue JA, Zanzonico P, Pugachev A, et al. Assessment of regional tumor hypoxia using ${ }^{18} \mathrm{~F}$-fluoromisonidazole and ${ }^{64} \mathrm{Cu}(\mathrm{II})$-diacetyl-bis $\left(\mathrm{N}^{4}\right.$ methylthiosemicarbazone) PET: comparative study featuring microPET imaging, $\mathrm{pO}_{2}$ probe measurement, autoradiography, and fluorescent microscopy in the R3327-AT and FaDu rat tumor models. Int J Radiat Oncol Biol Phys. 2005;61: 1493-1502. 